\title{
PARTISIPASI MAHASISWA TERHADAP LINGKUNGAN FISIK KAMPUS
}

\author{
${ }^{1}$ Narwati, ${ }^{2}$ Rusmiati, ${ }^{3}$ Rachmaniyah \\ 1, 2, 3, Dosen Poltekkes Kemenkes Surabaya
}

\begin{abstract}
Abstrak
Tujuan penelitian untuk mendapatkan gambaran partisipasi mahasiswa terhadap kebersihan lingkungan kampus Politeknik Kesehatan Surabaya. Metode penelitian bersifat deskriptif untuk memperoleh gambaran partisipasi mahasiswa terhadap kebersihan lingkungan. Populasi dalam penelitian ini adalah seluruh civitas akademik Jurusan Kesehatan Lingkungan Surabaya dan Jurusan Gizi yang masih aktif, sejumlah 389 siswa. Sampel yang diambil dengan menggunakan teknik Stratified Random Sampling, sehingga jumlah sampel diperoleh sebanyak 98 siswa. Teknik pengumpulan data melalui wawancara menggunakan kuesioner dan teknik observasi menggunakamn formulir pengamatan. Hasil penelitian menunjukkan 59 orang $(60,2 \%)$ mahasiswa bersikap cukup baik terhadap kebersihan lingkungan. Kebersihan 9 ruang kelas kampus $(56,25 \%)$ dikategorikan kurang bersih dan kondisi ruang kantor 8 komponen $(50 \%)$ dikategorikan kurang bersih. Bentuk partisipasi mahasiswa $54(55,1 \%)$ dikategorikan cukup aktif. Hal ini dikarenakan rutinitas pelaksanaan kegiatan Jumat Bersih setiap 2 minggu sekali. Disimpulkan bahwa partisipasi mahasiswa terhadap kebersihan lingkungan kampus cukup baik. Namun perlu dilakukan pemahaman, motivasi dan evaluasi program agar dapat ditindaklanjuti di masa yang akan datang.
\end{abstract}

Kata kunci: Partisipasi mahasiswa, kebersihan lingkungan, sikap mahasiswa.

\section{Abstract}

The aim of research to get an overview of student participation on environmental cleanliness of Surabaya Polytechnic Health campus. The research method is descriptive to gain an overview of student participation on environmental cleanliness. The population in this study are all the academic community Surabaya Department of Environmental Health and Nutrition Department is still active, a number of 389 students. Samples were taken using Stratified Random Sampling technique, so that the number of samples obtained by 98 students. Collection of data through interviews using questionnaires and observation techniques used observation form. The results showed $59(60.2 \%)$ of students behaved pretty well against environmental cleanliness. Cleanliness 9 classrooms campus (56.25\%) categorized as less clean and the condition of the office space 8 parts (50\%) categorized as less clean. Student participation form 54 (55.1\%) were categorized fairly active. This is because the routine implementation of the Clean Friday every two weeks. It was concluded that the participation of students to the campus environment is quite good hygiene. But the necessary understanding, motivation and evaluation of the program to be followed in the future

Keywords : Student participation, environmental cleanliness., the attitude of the students.

\section{PENDAHULUAN}

Keadaan lingkungan kampus yang sehat sangat dibutuhkan sebagai daya dukung kenyamanan dalam belajar. Terciptanya lingkungan sehat di area kampus akan memberikan suasana nyaman dan pembelajaran menjadi optimal bagi para mahasiswa. Dalam jangka panjang, lingkungan yang sehat akan menghasilkan kinerja para staf meningkat dan prestasi mahasiswa juga demikian.
Menurut Notoatmodjo (2012), partisipasi masyarakat di bidang kesehatan berarti keikutsertaan seluruh anggota masyarakat dalam memecahkan masalah kesehatan mereka sendiri. Di dalam hal ini, masyarakat sendirilah yang aktif memikirkan, merencanakan, melaksanakan, dan mengevaluasikan program-program kesehatan masyarakatnya. Institusi kesehatan hanya sekadar memotivasi dan 
membimbingnya. Partisipasi setiap anggota masyarakat dituntut suatu kontribusi atau sumbangan. Kontribusi tersebut bukan hanya terbatas pada dana dan finansial saja tetapi dapat dalam berbentuk daya dan ide. Dalam hal ini dapat diwujudkan di dalam $4 \mathrm{M}$, yakni manpower (tenaga), money (uang), material (bendabenda lain seperti kayu, bambu, beras, batu), dan mind (ide atau gagasan).

Tujuan penelitian ini untuk memperoleh gambaran partisipasi mahasiswa melalui sikap terhadap kebersihan lingkungan, menilai kebersihan lingkungan Kampus serta memperoleh gambaran bentuk partisipasi mahasiswa terhadap kebersihan lingkungan kampus.

\section{METODE PENELITIAN}

Jenis penelitian adalah deskriptif kuantitatif. Sampel penelitian berjumlah 98 orang dari jumlah populasi 389 mahasiswa Jurusan Kesehatan Lingkungan dan Jurusan Gizi Poltekkes Surabaya.

Pengumpulan data dilakukan melalui teknik wawancara terhadap mahasiswa dan observasi terhadap komponen penilaian dengan menggunakan formulir wawancara dan formulir observasi serta dilakukan pencatatan mengenai tingkat kebersihan bangunan (lantai, dinding, langit-langit dan jendela) serta kebersihan halaman.

\section{HASIL PENELITIAN}

\section{Sikap Mahasiswa}

Tabel 1. Sikap Mahasiswa Terhadap Kebersihan di dalam Gedung Jurusan Kesehatan Lingkungan dan Jurusan Gizi Poltekkes Kemenkes Surabaya

\begin{tabular}{lccc}
\hline Kategori & Interval & Jumlah & $\%$ \\
\hline Baik & $\geq 51,4$ & 39 & 39,8 \\
\hline Cukup & $32,7-51,3$ & 59 & 60,2 \\
\hline Kurang & $\leq 32,69$ & 0 & 0 \\
\hline \multicolumn{2}{c}{ Jumlah } & 98 & 100 \\
\hline
\end{tabular}

Distribusi mahasiswa berdasarkan indikator sikap tentang kebersihan diperoleh hasil bahwa 59 mahasiswa $(60,2 \%)$ memiliki kategori sikap cukup, sedangkan yang memiliki kategori sikap baik sebanyak 39 orang $(39,8 \%)$.

\section{Bentuk Partisipasi Mahasiswa}

Tabel 2. Distribusi frekuensi partisipasi mahasiswa terhadap kebersihan kampus di Jurusan Kesehatan Lingkungan dan Jurusan Gizi Poltekkes Kemenkes Surabaya

\begin{tabular}{lccc}
\hline Kategori & Interval & Jumlah & $\%$ \\
\hline Baik & $\geq 34$ & 0 & 0 \\
\hline Cukup & $23-33$ & 54 & 55,1 \\
\hline Kurang & $\leq 22,9$ & 44 & 44,9 \\
\hline \multicolumn{2}{c}{ Jumlah } & 98 & 100 \\
\hline
\end{tabular}

Partisipasi mahasiswa terhadap kebersihan kampus dapat dilihat pada tabel 2., menunjukkan bahwa 54 orang $(55,1 \%)$ mahasiswa telah berpartisipasi cukup aktif, namun masih dijumpai 44 (44,9\%) mahasiswa kurang aktif dalam kegiatan kebersihan lingkungan di kampus.

\section{PEMBAHASAN \\ Sikap Mahasiswa}

Sikap merupakan reaksi atau respon yang masih tertutup dari seseorang terhadap stimulus atau objek. Sikap belum merupakan suatu tindakan atau aktivitas, akan tetapi merupakan predisposisi (kecenderungan umum).

Munir (2010) mengatakan bahwa dalam bersikap selalu ada obyek yang disikapi. Obyek disini dalam arti luas seperti masalah atau pokok persoalan, tindakan, perilaku, cara kerja, orang atau peristiwa. Jika subyek sudah menentukan sikap mereka terhadap lingkungan hidup mereka, khususnya bersikap baik, mereka akan berusaha untuk menjaga kebersihan lingkungan.

Sikap subyek terhadap kebersihan lingkungan adalah predisposisi (kecenderungan umum) yang dipelajari atau dibentuk dalam merespon secara konsisten terhadap satuan ruang, termasuk lingkungan fisik (non hayati) yang didasarkan pada komponen kognitif, yaitu pengetahuan dan persepsi mereka 
mengenai masalah lingkungan, komponen afektif yaitu emosi atau perasaan mereka terhadap lingkungan, dan perilaku mereka terhadap lingkungan. Apabila dilakukan hubungan dengan sikap mahasiswa terhadap kebersihan lingkungan di lingkungan kampus, maka diharapkan mahasiswa mampu bersikap positif tentang lingkungan dengan menjaga lingkungan terutama kebersihan lingkungan kampus, baik di dalam gedung maupun di luar gedung.

\section{Kebersihan Lingkungan Kampus}

Tingkat kebersihan lingkungan di Kampus Jurusan Kesehatan Lingkungan dan Jurusan Gizi Poltekkes Kemenkes Surabaya dikategorikan kurang, karena sebanyak 9 komponen $(56,25 \%)$ dalam kondisi kurang dijaga kebersihannya. Begitupun hasil pengamatan terhadap kebersihan ruang di dalam kampus berkategori kurang. Menurut Alex S. Nitisemito (2002) bahwa lingkungan kerja fisik adalah segala sesuatu yang ada di sekitar para pekerja yang dapat mempengaruhi dirinya dalam menjalankan tugas-tugas yang dibebankan, misalnya penerangan, suhu udara, ruang gerak, keamanan, kebersihan, musik dan lain-lain.

Kebersihan lingkungan harusnya senantiasa dilakukan dimanapun seseorang tinggal, termasuk di dalam kampus sehinggadengan lingkungan yang bersih, akan memberikan motivasi bagi mahasiswa dalam melaksanakan pembelajaran yang pada akhirnya akan memberikan prestasi.

Rais (2014) dalam karya ilmiahnya mengemukakan bahwa kebersihan sangat mempengaruhi konsentrasi belajar siswa. Jika kelas bersih, indah dan tertata rapi maka kemungkinan besar kenyamanan dalam proses pembelajaran akan tercapai, selain itu konsentrasipun bisa lebih fokus, dengan begitu sistem kerja otak akan semakin meningkat. Kebersihan lingkungan sekolah merupakan salah satu bagian dari lingkungan belajar yang memberikan rasa nyaman bagi siswa dalam mengikuti proses belajar mengajar yang memberikan pengaruh positif terhadap prestasi belajar. $\mathrm{Hal}$ ini sesuai dengan hasil penelitian Ningrum (2013) dimana selain motivasi belajar, lingkungan belajar akan mempengaruhi prestasi belajar. Didapatkan bahwa jika lingkungan belajar mengalami kenaikan $1 \%$, maka prestasi belajar akan mengalami peningkatan sebesar 0,366.

Menurut Suit-Almasdi (1996), sikap mahaiswa dalam implementasi kebersihan lingkungan dapat dibedakan menjadi dua bentuk, yaitu sikap dalam bentuk fisik yang merupakan tingkah laku yang terlahir dalam bentuk gerakan dan perbuatan fisik (SuitAlmasdi 1996). Hal ini tercermin pada sikap dalam membersihkan ruang yang belum sepenuhnya dilakukan oleh mahasiswa, sehingga diperlukan motivasi agar mahasiswa tergerak untuk melakukan kegiatan tersebut. Menurut Ranupandoyo dan Husnan dalam Rita Jayani Dudung (2004), motivasi yang diberikan kepada seseorang dapat meliputi 1) motivasi positif, yaitu proses mencoba mempengaruhi orang lain agar menjalankan sesuatu yang kita inginkan dengan cara memberikan kemungkinan untuk mendapatkan hadiah. 2) Motivasi negatif, yaitu proses mempengaruhi seseorang agar mau melakukan sesuatu yang kita inginkan, tetapi melalui kekuatan ketakutan, seperti pemberian sangsi.

\section{Bentuk Partisipasi Mahasiswa}

Menurut Keith Davis dalam Santoso, 1988) bentuk-bentuk partisipasi masyarakat adalah berupa; pikiran, tenaga, keahlian, barang dan uang. Bentuk partisipasi masyarakat ini dilakukan dalam berbagai cara, yaitu; konsultasi, biasanya dalam bentuk jasa; sumbangan spontanitas berupa uang dan barang; mendirikan proyek yang sifatnya berdikari dan dibiayai oleh masyarakat sendiri; sumbangan dalam bentuk kerja; ksi massa,; mengadakan pembangunan di dalam keluarga; dan membangun proyek masyarakat yang bersifat otonom.

Jurusan Kesehatan Lingkungan telah mengadakan program Jumat bersih, namun hasil observasi lapangan terhadap 
kebersihan kampus baik kampus jurusan kesehatan lingkungan dan jurusan gizi dikategorikan kurang. Hamijoyo dalam Desmawangga (2013), mengungkapkan bahwa partisipasi tenaga adalah partisipasi yang diberikan dalam bentuk tenaga untuk pelaksanaan usaha-usaha yang dapat menunjang keberhasilan suatu program. Sehingga untuk mewujudkan kampus yang bersih, diperlukan partisipasi seluruh civitas akademika, terutama mahasiswa dan perlu dilakukan secara rutin, tidak hanya dalam kegiatan Jumat bersih, namun perlu diadakan piket kelas yang perlu dilakukan pengawasan dalam pelaksanaannya.

\section{KESIMPULAN}

Sikap mahasiswa terhadap kebersihan lingkungan kampus berkategori cukup baik. Kondisi kebersihan kampus dikategorikan kurang. Bentuk partisipasi mahasiswa terhadap kebersihan lingkungan kampus dikategorikan cukup.

\section{SARAN}

Diperlukan motivasi, arahan dan evaluasi program kegiatan bagi mahasiswa dalam berpartisipasi terhadap kebersihan kampus.

\section{DAFTAR PUTAKA}

Desmawangga C., (2013). Studi tentang partisipasi mahasiswa program studi administrasi negara dalam organisasi kemahasiswaan di Fakultas IImu Sosial dan IImu Politik Universitas

Dudung, R.J., (2004). Tingkat motovasi kerja dan hubungannya terhadap curahan kerja karyawan/ karyawati Universitas Negeri Papua di Manokwari, Fak. Pertanian dan Teknologi Pertanian, UNP.

Manokwari R., Stephen P., dan Judge T., (2007). Organizational behavior. Edisi 12. Pearson Prentice Hall.

Mulawarman, (2013). Ilmu Administrasi, EJournal: 1 (2): 683-697

Munir M.A., (2010). Pembelajaran Afeksi. https://www.google.co.id, Diakses 2 Maret 2015.

Notoatmodjo S., (2012) Promosi Kesehatan dan Perilaku Kesehatan. Jakarta: Rineka Cipta,

Rais P., (2014). Pengaruh kebersihan kelas terhadap konsentrasi belajar siswa kelas XI IPA II, Dinas Pendidikan Nasional Sma Negeri 1 Kayuagung.

Santoso, S., (1988). Partisipasi, komunikasi, persuasi dan disiplin dalam pembangunan nasional. Bandung: Alumni.

Suit-Almasdi, J., (1996). Aspek sikap mental dalam manajemen sumber daya manusia. Ghalia Indonesia. 